
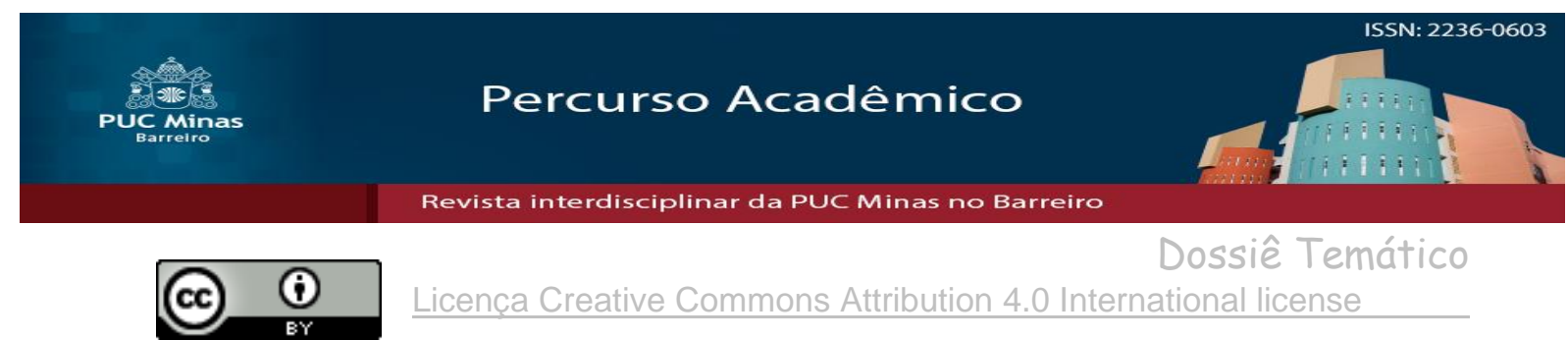

Licença Creative Commons Attribution 4.0 International license

\title{
Educação financeira: aplicação das lições do Pai Rico, Pai Pobre à realidade de um jovem brasileiro
}

\author{
Financial education: applying the lessons of Rich Dad, Poor Dad to the reality of a \\ young Brazilian
}

\begin{abstract}
RESUMO
O presente caso para ensino tem como objetivo favorecer a aplicação da obra de Pai Rico, Pai Pobre à realidade brasileira e propiciar uma reflexão acerca da importância da educação financeira no Brasil, do planejamento financeiro e dos investimentos para as Pessoas Físicas, com foco nos jovens que estão iniciando a vida profissional. Portanto a abordagem favorece o processo de planejamento para a aposentadoria por meio de uma gestão própria de investimentos, diante da abordagem sobre finanças pessoais, de um debate sobre finanças pessoais através da metodologia do Livro Pai Rico, Pai Pobre, modelo mundialmente conhecido e de grande relevância. Para o desenvolvimento do caso, considerou-se que o estudante brasileiro possui 25 anos e não tem conhecimento em educação financeira, não tendo se organizado financeiramente, tampouco realizado controle de gastos ou ter acesso a administração de investimentos. Com tal proposta espera-se que os leitores se coloquem no papel de João e realizem uma análise acerca das situações apresentadas, procedendo uma interação com o instrumento de apoio a decisão exposto pela planilha, a fim de atingir sua meta de aposentadoria. Ao favorecer o espaço de debate sobre a importância a respeito das finanças pessoais com vistas a um planejamento de longo prazo espera-se desenvolver a competência dos alunos quanto a educação financeira no Brasil. A utilização da metodologia do Pai Rico, Pai Pobre para os jovens brasileiros é mostrar a necessidade de iniciar o quanto antes a construção da própria riqueza e dessa forma garantir um futuro estável num país onde a seguridade social demonstra grande desequilíbrio financeiro. $\mathrm{O}$ caso foi elaborado para adoção em qualquer curso ou treinamento na área gerencial considerando a competência: compreender o contexto em que se insere como pessoa e cidadão, suas responsabilidades sociais e éticas na construção do futuro da sociedade.
\end{abstract}

Palavras-chave: Educação financeira. Finanças. Pai Rico, Pai Pobre.

\begin{abstract}
The present teaching case aims to favor the application of Pai Rico, Pai Pobre to the Brazilian reality and provide a reflection on the importance of financial education in Brazil, financial planning and investments for Individuals, with a focus on young people who are starting their professional lives. Therefore, the approach favors the retirement planning process through its own investment management, in front of the personal finance approach, of a debate on personal finance through the methodology of the book Rich Dad, Poor Dad, a worldwide known and great model. relevance. For the development of the case, it was considered that the Brazilian student is 25 years old and has no knowledge of financial education, has not been financially organized, has not controlled expenses or has access to investment management. With this proposal, readers are expected to put themselves in the role of João and carry out an analysis of the situations presented, interacting with the decision support instrument exposed by the spreadsheet, in order to reach their retirement goal. By favoring the space for debate on the importance of personal finance with a view to long-term planning, it is expected to develop students' competence regarding financial education in Brazil. The use of the Rich Dad, Poor Dad methodology for young Brazilians is to show the need to start

Artigo recebido em 13 de setembro de 2021 e aprovado em 02 de outubro de 2021

${ }^{1}$ Graduanda do curso de Ciências Contábeis (PUC Minas), Brasil. E-mail: agneslima@yahoo.com.br

${ }^{2}$ Graduanda do curso de Ciências Contábeis (PUC Minas), Brasil.E-mail: luane.custodio@sga.pucminas.br

${ }^{3}$ Graduanda do curso de Ciências Contábeis (PUC Minas), Brasil.E-mail: paulinegerlin@gmail.com

${ }^{4}$ Doutor em Administração (UFMG) , Docente (PUC Minas), Brasil. E-mail: sidneylino@ pucminas.br
\end{abstract}


building their own wealth as soon as possible and thus ensure a stable future in a country where social security shows a great financial imbalance. The case was prepared for adoption in any course or training in the management area, considering the competence: understanding the context in which it operates as a person and citizen, its social and ethical responsibilities in building the future of society.

Keywords: Financial education. Finance. Rich Dad, Poor Dad.

\section{INTRODUÇÃO}

Belo Horizonte, terça-feira, às vinte horas e cinquenta minutos, João, que acaba de completar 25 anos, aluno do curso de Ciências Contábeis na PUC Minas, estava conversando com sua amiga Laura no intervalo, enquanto aguardava a próxima aula. Ele estava em uma situação nova e desafiante! Ele conseguiu seu primeiro emprego em uma empresa, e João estava iniciando sua vida profissional e não sabia ainda o que fazer com o dinheiro recebido, como gastar e como proceder de agora em diante. Suas dúvidas contemplavam:

Como se planejar? Por onde começar? O que fazer com o dinheiro? É possível levar uma vida independente a partir de agora?

O estudante não dispunha de conhecimentos relativos à educação financeira, tampouco sobre planejamentos de longo prazo e a única coisa que ele afirmava com segurança é que gostaria de se aposentar aos 65 anos com uma renda do Seguro Social e uma poupança adquirida ao longo dos anos de trabalho.

\section{ANTECEDENTES}

João nunca se preocupou com assuntos relacionados a finanças e orçamentos, pois sempre morou com os pais e todas suas necessidades eram supridas por eles. Os pais de João são professores de escola particular (professores de escola pública), possuem certa estabilidade no trabalho e uma renda familiar que permite a realização da compra da casa própria , um carro financiado e sabem da importâcia dos estudos para o único filho, sendo assim, estão dispostos a custear o ínicio da vida acadêmica de João. Não possuem qualquer formação na área de finanças, possuem apenas um plano de regime de previdência própria da Prefeitura onde trabalham. Em 2018, iniciou a graduação na área gerencial, em uma faculdade de renome na própria cidade que vive, em Belo Horizonte, Minas Gerais. Durante a gradução João foi percebendo a importância das finanças, de um bom planejamento e controle para o sucesso de uma empresa quanto para a sua própria vida pessoal. O ínicio da vida profissional de João se dá em programa de estágio 
na área de controladoria em uma multinacional indicado pela Faculdade em que estudava. João executava atividades relacionadas a fechamento contábil, controle de verba, orçamento previsto versus realizado. Desempenhou suas funções com muito interesse, apresentou bons resultados e ao fim do período de estágio foi contratado.

\section{O INÍCIO DA INDEPENDÊNCIA}

João sempre quis sair da casa dos pais e morar sozinho, mas estava totalmente inseguro porque sempre se apoiou nos pais e nunca participou dos problemas que envolvem um planejamento financeiro e orçamento familiar. No entanto, o estágio na área de controladoria lhe despertou o interesse para o assunto de finanças e logo ele percebeu que precisaria aplicar aqueles exemplos para sua vida, planejando-a de forma similar aos planos que teve oportunidade de acompanhar no ambiente corporativo. Assim, João, que nunca possuiu uma fonte de renda, nunca precisou e não sabia como se organizar financeiramente e nunca fez controle dos gastos, deparou-se com um horizonte totalmente novo. Com base neste cenário, ele entendeu que aquele momento de sua vida seria marcado por uma completa mudança de atitudes/posturas que poderiam fazer diferença no decorrer de toda a sua vida. Desta forma, João compreende a relevância do momento e vai buscar informações para desenvolver um planejamento orçamentário pessoal, tentando compreender os comportamentos financeiros que possam levá-lo a uma situação de equilíbrio e saúde financeira. $\mathrm{O}$ objetivo dele era se preparar para ser independente financeiramente dos pais e conseguir identificar os gastos para gerir seus recursos. $\mathrm{O}$ estudante foi então instruído a evitar dívidas, controlar seus gastos e economizar parte de sua receita mantendo uma reserva emergencial e alocando suas economias em investimentos bem planejados. Assim, por meio dessa gestão independente de suas aplicações ele espera que no futuro estes investimentos possam lhe subsidiar por meio de uma renda passiva, dando-lhe conforto e segurança financeira em seu período de aposentadoria.

\section{O PROBLEMA}

Construir uma metodologia de treinamento para os funcionários de empresas, como foco, em funcionários com idade média de 25 anos (entre 20 e 30 anos) como preparação para a aposentadoria, por meio de uma gestão independente de investimentos. A primeira parte aborda recursos necessários (Educação Financeira) e a segunda parte, o foco no planejamento de aposentadoria (Investimento). Para tanto, foi considerado o 
cenário médio (por meio de simulações), ou seja, aposentadoria aos 65 anos com taxa média de retorno dos investimentos de $5 \%$ e aumento real na renda do indivíduo de $2 \%$ ao ano. Diante da modelagem assumida, considerou-se que João teria que poupar cerca de $14 \%$ do seu salário líquido, para ter um retorno no período de aposentadoria, com uma expectativa de vida de 80 anos. Como realizar um planejamento financeiro, para ter equilíbrio entre o que ganha e o que gasta?

\section{NOTAS DE ENSINO}

\subsection{Fontes e métodos de coleta}

O caso para ensino apresentado é fictício. O mesmo foi elaborado pelo embasamento em livoros e artigos, além do conhecimento dos autores quanto à temática apresentada.

\subsection{Objetivos de ensino}

O presente caso tem o objetivo de apresentar o modelo do Pai Rico, Pai Pobre à realidade brasileira, permitindo ao jovem assimilar de modo prático, ofertando leitura de cenários para encorajar o início de sua jornada de investimentos. A proposta é proporcionar o raciocínio e a reflexão dos leitores sobre as sugestões e alternativas mostradas no caso, para que se coloquem no papel do jovem, analisando as propostas apresentadas, bem como permitir um debate sobre a importância a respeito das finanças pessoais.

A utilização da metodologia do Pai Rico, Pai Pobre para os jovens brasileiros é mostrar a necessidade de iniciar o quanto antes a construção da própria riqueza e dessa forma garantir um futuro estável num país onde a seguridade social demonstra grande desequilíbrio financeiro. A idade mínima para se aposentar pelo INSS é 65 anos para homens, e para mulheres é 62 anos.

\subsection{Utilização recomendada}

O caso foi elaborado para utilização no projeto interdisciplinar de educação financeira, tendo como ancoragem as abordagens orçamentárias, financeiras e sociais. 
Almeja-se que o caso contribua para que os alunos desenvolvam entendimentos sobre educação financeira, planejamento financeiro e investimentos.

\subsection{Plano de aula}

A fim de permitir a adoção do método de estudo do caso em aula, após a leitura do mesmo, sendo exposto o assunto e esclarecido os critérios de estruturação dos três cenários projetados, propõe-se que os alunos sejam divididos em grupos para discussão desenvolvendo a análise de uma questão para posterior socialização a turma, sendo cada grupo responsável por um tópico:

\subsubsection{Discussão de finanças comportamentais:}

a) Analisar a viabilidade de executar as despesas e investimentos propostos, considerando o padrão de vida de João e sua família;

b) Propor dicas de como evitar gastos excessivos, imprevistos financeiros ao longo da vida e propor um fundo de emergência;

c) Avaliar as diferentes realidades financeiras do método Pai Rico, Pai Pobre para o Brasil e suas peculiaridades quanto a uma previdência complementar. O que se busca é uma renda passiva em sua aposentadoria;

d) Discutir métodos de controle de impulsos emocionais, para mudar hábitos financeiros. Como P.A.R.D. (perceba-análise-reflita-decida), método retirado do Curso Inteligência Financeira (2020), da Escola Conquer;

e) Considerar o $13^{\circ}$ salário e Bônus como parte do plano de metas, sempre considerando a proporção de investimento de $14 \%$ como oportunidades de investimento;

f) Considerar as possibilidades de renda extra.

g) Avaliar o patrimônio familiar adquirido e seu endividamento. Destaca-se aqui imóvel próprio e veículo;

4.4.2 A segunda etapa propõe o início de um planejamento financeiro:

(a) Qual objetivo a ser alcançado? Existe uma preocupação em se fazer uma reserva de capital para aposentadoria, diante disso, expor a importância de que estas decisões deverão ser tomadas o quanto antes iniciar a vida financeira;

(b) Colocar as metas separadas por período no curto, médio e longo prazo. 
(c) Propor a divisão de gastos por categoria entre 50\% custos fixos, 36\% gastos adicionais e $14 \%$ para investimentos;

(d) Reavaliar, sempre que necessário, os gastos e como controlá-los:

Uma forma simples de organizar os gastos de cada mês é utilizando o Aplicativo Guia Bolso. 100\% gratuito que oferece recursos para separar as compras por categorias. De tal maneira, será possível organizar os gastos de cada mês.

(e) Discutir sobre a importância da reserva de emergência e propor que a quantidade de 6 meses de gastos básicos como meta: Segundo o modelo do Pai Rico, Pai Pobre uma das formas de se medir o quanto uma pessoa é rica é pelo número de anos que ela conseguiria viver mantendo seu padrão de vida, mesmo que ela parasse de trabalhar. Pois bem, estamos trazendo o modelo para a realidade Brasil e precisamos considerar o alto índice de desemprego e para isso a reserva de emergência se torna importante. A reserva de emergência, como o próprio nome sugere, é uma espécie de fundo monetário. A ideia é que esse dinheiro não seja tocado, a não ser para situações de urgências ou, então, para a realização de algum sonho que envolva custos mais elevados.

Não existe um investimento mínimo para a reserva de emergência. O ideal é adaptar de acordo com a realidade e entender o quanto é possível separar sem que o orçamento seja prejudicado.

Considerar os gastos fixos no mês e realizar a programação.

Exemplo: Salário R \$ 3.000,00

Anotar os gastos fixos (considerando a ideia de sair da casa dos pais)

Água, luz, telefone e gás

Aluguel e condomínio

Transporte

Considerando um custo de vida de $\mathrm{R} \$ 1.000,00$, a reserva de emergência precisa ser de $\mathrm{R} \$ 6.000,00$.

Recebimentos como $13^{\circ}$ Salário, participação nos lucros deve realizar a reserva de $14 \%$ do valor recebido;

(f) Estudar gastos adicionais e sua viabilidade, como a compra de um carro e o custo efetivo de manter um carro mensalmente, considerando IPVA, Licenciamento, seguro e depreciação ou a opção de carro por assinatura, que é uma modalidade de aluguel, 
no qual os custos com revisão, impostos, seguros, dentre outros estão embutidos no valor da mensalidade;

(g) Introduzir conceitos sobre Balanço Patrimonial, DRE e Fluxo de caixa, demonstrando a possibilidade de que a pessoa física tenha suas próprias demonstrações financeiras, conforme livro Pai Rico, Pai Pobre.

Será apresentada a planilha de excel, do livro Pai Rico, Pai Pobre, com 3 cenários distintos: o primeiro será aos 25 anos, no contexto de estar em seu primeiro emprego no regime CLT (Consolidação das Leis Trabalhistas), no qual João se prepara para se tornar independente dos pais financeiramente, importante destacar que estes arcavam com as suas despesas até então. Foi considerada como outras despesas, o valor retido na fonte referente ao INSS. Não há, também, renda de ativos tangíveis ou de portfólio, como juros e dividendos, uma vez que a construção do patrimônio iniciará nesse momento. No segundo cenário, João tem 46 anos, está casado, foi considerado o salário do casal (salário \#1 refere-se a João e salário \#2 refere ao de sua esposa), tem 1 filho, um carro por assinatura e casa própria financiada. Por fim, no cenário 3, João está com 65 anos e passará a receber aposentadoria pelo governo e como renda complementar, inicia-se o processo de retirada do dinheiro que foi investido ao longo de sua vida profissional, foi considerado também, o valor recebido por sua esposa (salário \#1 valor de INSS recebido por João e salário \#2 valor de INSS recebido por sua esposa).

\subsection{Sugestão de questões para discussão}

a) A partir do caso de ensino, pode-se observar que João não tem conhecimentos em educação financeira, e sendo este um problema de grande parte dos brasileiros. Historicamente no Brasil vivemos sobre grandes ameaças de instabilidade no emprego, inflação e por isso culturalmente a população age financeiramente de forma imediata e sem planejamento. Assim, torna-se importante o planejamento financeiro pessoal enquanto se é jovem para viver com mais tranquilidade e se planejar para a aposentadoria. b) João está iniciando a vida profissional e o planejamento financeiro, como estudante de contabilidade, possui conhecimentos sobre Balanço Patrimonial, DRE e Fluxo de caixa voltados para a Pessoa Jurídica. Descreva a definição de ativos e patrimônio líquido segundo o banco e segundo pai rico e classifique imóveis e bens de consumo duráveis em ativo e passivo. 
c) Discuta sobre a importância do Balanço Patrimonial, DRE e Fluxo de caixa voltados para a Pessoa Física e crie cenários. Em sua opinião, qual é o melhor cenário? Considerar o mesmo cenário em contextos com crises econômicas.

d) Avalie as vantagens de criar um calendário mensal de despesas adequado à sua realidade. Qual sua perspectiva profissional? Formou família? É possível projetar esse cenário?

f) Apresente formas e alternativas de consumo consciente, bem como formas de obter renda extra, considerando aspectos econômicos e emocionais. Calcule o quanto a economia impactaria no Fluxo de caixa pessoal.

\section{EMBASAMENTO TEÓRICO}

A educação financeira consiste em conhecimentos e competências que auxiliam a escolhas inteligentes referentes a dinheiro, transações financeiras e consumo. A perspectiva de tal abordagem visa favorecer a conquista de certo bem-estar e tranquilidade na vida. É também, um meio básico e eficaz de conquistar a qualidade de vida no nível individual, da família, da sociedade e de uma nação (FERREIRA, 2017). Entretanto, esta possibilidade apenas se torna viável quando se abordar as Finanças Comportamentais, também conhecida, como a alfabetização financeira. Compreender o que move o consumo e como estabelecer o controle sobre ele é de extrema relevância na busca do entendimento da realidade econômica, percebendo a influencia na tomada de decisões de projetos individuais e familiares, seja para o consumo, seja na exposição ao risco.

A educação financeira, a administração e o planejamento dos recursos são fatores que influenciam a vida das pessoas, pois os jovens tem consciência da importância de fazer poupança, mas desconhecem como podem aplicar seus recursos para ter uma rentabilidade adequada.

O comportamento individual em relação ao dinheiro, é influenciado por diversos fatores, como por exemplo, contexto social, crise econômica e pandemia, então, é importante agir com inteligência financeira e saber gastar de forma consciente, bem como o controle de impulsos emocionais. Assim, será possível evitar dívidas e ter sobra de dinheiro para investir conforme a meta estabelecida (CONQUER, 2020). 
É suma relevância entender a forma como se gasta e mudar comportamentos e hábitos de consumo, pois é necessário compreender a influência que as finanças comportamentais e os hábitos possuem sobre as decisões financeiras, para que haja mais consciência e melhor gerenciamento dos gastos (CONQUER, 2020).

O planejamento financeiro, conforme Gama; Correia (2012), é um meio de orientar, controlar e coordenar as ações da família para o alcance dos objetivos. Por meio de um planejamento e um orçamento doméstico, é possível aproveitar as oportunidades de investimento, identificar o grau de endividamento aceitável, bem como determinar a quantidade dos lucros aferidos (GAMA e CORREIA, 2012).

O planejamento financeiro pessoal, consiste em planejar, projetar uma direção para que se alcance os objetivos traçados e as metas estabelecidas, no qual irá gerir os recursos de acordo com uma estratégia, buscando manter ou amentar as riquezas, com a finalidade de formar patromônio. Segundo Melassise; Kfouri; Sampaio (2018), “estabelecer um planejamento financeiro, nada mais é do que organizar-se em relação a suas finanças e traçar estratégias para alcançar uma meta. É importante que você tenha a sua meta bem definida, ela direcionará o seu planejamento e te motivará a cumprí-lo”.

O planejamento familiar é eficiente quando há equilíbrio. E este ocorre quando se gasta menos do que ganha e investindo a diferença com regularidade. É necessário ter conhecimento detalhado dos gastos mensais e adotar medidas que viabilizem a poupança regular, assim, será possível ter mais qualidade no consumo.

É essencial definir alguns conceitos, conforme Kiyosaky (2000), "um ativo é algo que põe dinheiro no meu bolso. Um passivo é algo que tira dinheiro do meu bolso". Ativo é, portanto, o que gera renda. Enquanto passivo gera obrigações. A estrutura conceitual da contabilidade, NBC TG 00, apregoa que ativo é "um recurso econômico presente controlado pela entidade como resultado de eventos passados", enquanto passivo é "uma obrigação presente da entidade de transferir um recurso econômico como resultado de eventos passados".

A planilha em excel, disponibilizada para download no site Resumo Cast, do Pai Rico, Pai Pobre, do Robert Kiyosaky, é dividida em três partes, no canto superior esquerdo há o Fluxo de entradas e saídas, dividido em Receitas, Despesas e Fluxo de Caixa. Na parte inferior, há o Balanço Financeiro, no qual se encontram os Ativos, Passivos e Patrimônio Líquido. Já no canto superior direito, verificam-se os Indicadores Financeiros, nos quais é possível realizar análises, que permitem a identificação da situação financeira. 
As receitas são divididas em salários, renda de ativos tangíveis e rendas de ativos de portfólio, contribuindo, portanto, para que o fluxo de caixa seja positivo. Já as despesas, são os custos de vida, montante gasto para sustentar uma família. O fluxo de caixa representa a diferença entre receitas e despesas (receitas - despesas).

Acerca do Balanço Financeiro, os ativos segundo o banco incluem os ativos acessórios, nos quais não geram rendimentos.

No caso de estudo em questão foram traçados três cenários:

No primeiro cenário, João em seu início de carreira terá sua primeira receita (Salário R \$ 3.000,00) e irá avaliar qual o valor que possui de despesas, dentre elas o valor retido como Imposto de Renda e INSS (outras despesas), as suas despesas com alimentação e vestuário e as despesas com cartão de crédito que pretende adquirir para demais gastos. Por estar ingressando no mercado de trabalho e ainda morar com os pais, a quantidade de despesas são pequenas e no primeiro momento ele pretende fazer uma reserva de emergência, e para isso estipulou, após a suas pesquisas e aulas sobre educação financeira, que esta deve ser o valor correspondente a seis meses das suas despesas (6 X $\mathrm{R} \$ 1.738,80=10.432,80)$ e considerando sua remuneração atual como demonstrado na primeira tabela, seu fluxo de caixa (receitas - despesas) é de R $\$ 1.261,20$, levando João a observar que terá sua reserva em 9 meses.

\section{Quadro 1: Primeiro Cenário do João}

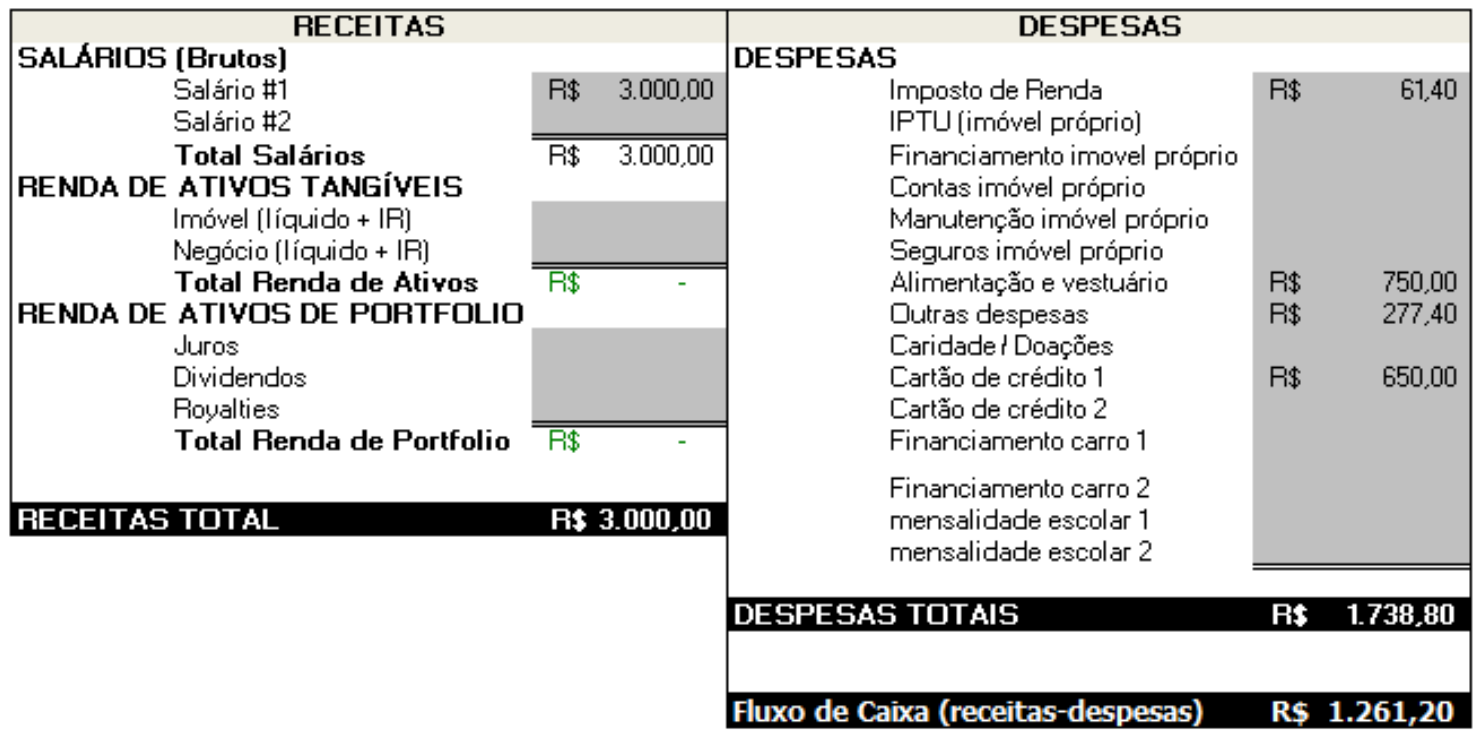

Fonte: Adaptado de Kiyosaki (2000)

Depois de observar qual o seu fluxo de caixa, João monta o seu balanço patrimonial, onde o seu primeiro investimento será classificado na conta "investimentos bancários", já que se tratando de um valor que será destinado a reserva de emergência, o 
seu destino será a aplicações de renda fixa. Desta maneira ele adquire um ativo (investimentos) com um patrimônio líquido equivalente.

Quadro 2: Primeiro cenário do João

\begin{tabular}{|c|c|c|c|c|c|}
\hline \multicolumn{3}{|l|}{ ATIVOS } & \multicolumn{3}{|l|}{ PASSIVOS } \\
\hline ATIVOS & & & PASSIVOS & & \\
\hline $\begin{array}{l}\text { Investimentos bancários } \\
\text { Açós } \\
\text { Títulos } \\
\text { Recebíveis } \\
\text { Imóveis (investimento) }\end{array}$ & $\mathrm{R} \$$ & $1.261,80$ & $\begin{array}{l}\text { Cartões de crédito } \\
\text { Financiamentos de carros } \\
\text { Financiamentos escolares } \\
\text { Hipotecas imobiliárias } \\
\text { Empréstimos pessoais } \\
\text { Gutros nassivos }\end{array}$ & & \\
\hline $\begin{array}{l}\text { \{Yolos dummecos-dineteces } \\
\text { Valor líquido dos negócios }\end{array}$ & & & $\begin{array}{l}\text { Dutros passivos } \\
\text { TOTAL DE PASSIVOS }\end{array}$ & Rs & - \\
\hline TOTAL DE ATIVOS & Rs & $1.261,80$ & & & \\
\hline $\begin{array}{l}\text { ATIVOS ACESSÓRIOS } \\
\text { Casa própria (moradia) } \\
\text { Automóveis para uso próprio } \\
\text { Dutros }\end{array}$ & & & & & \\
\hline TOTAL DE ATIVOS ACESSÓRI & Rs & - & & & \\
\hline Total de ATIYOS segundo o banco & Rs & $1.261,80$ & Patrimônio líquido segundo banco & RS & $1.261,80$ \\
\hline 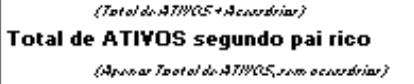 & Rs & $1.261,80$ & 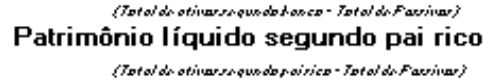 & Rs & $1.261,80$ \\
\hline
\end{tabular}

Fonte: Adaptado de Kiyosaki (2000)

A terceira parte da planilha tem por finalidade analisar a situação financeira através de indicadores, João investiu 42,04\% ("quanto você guarda"), e a relação de ativos/ despesas $(0,7)$ indicando a geração de riqueza em meses. O "Fast Track" indica a capacidade de geração de renda passiva que levará a independência financeira, ou seja, o indicador sendo maior que 1 , aponta que a sua renda passiva é suficiente para cobrir suas despesas.

\section{Quadro 3: Primeiro cenário do João}




\begin{tabular}{|c|c|}
\hline ANALISE & \\
\hline $\begin{array}{l}\text { Quanto você guarda? } \\
\text { Fluxo de CaixaReceitas Total } \\
\text {..'Deve esta aumentando }\end{array}$ & $42,04 \%$ \\
\hline $\begin{array}{l}\text { Seu dinheiro trabalha para você? } \\
\text { (Renda Ativos+Rienda Portf.) PReceitas Tota } \\
\text {.-Deve estar aumentando }\end{array}$ & $0,00 \%$ \\
\hline $\begin{array}{l}\text { Quanto você paga de imposto? } \\
\text { Imposto de rendaReceitas Total }\end{array}$ & $2,05 \%$ \\
\hline $\begin{array}{l}\text { Quanto você gasta para morar? } \\
\text { Despesas de moradialReceitas Tota } \\
\text {...mantenha abiano de } 33 \%\end{array}$ & $0,00 \%$ \\
\hline $\begin{array}{l}\text { Quanto você gasta em acessórios? } \\
\text { A.tivos Acessórios Ativos segundo t } \\
\text {..'mantenha abairo de } 33 \%\end{array}$ & $0,00 \%$ \\
\hline $\begin{array}{l}\text { Qual o seu retorno anual sobra ativos? } \\
\text { Rienda Ativos+Renda Port.tativos segundo } \\
\text {-'deve estar aumentando }\end{array}$ & $0,00 \%$ \\
\hline $\begin{array}{l}\text { Quanto rico você é? } \\
\text { Ativos segundo pai ricotDespesas Totais } \\
\text { '-'medido em Meses }\end{array}$ & 0.7 \\
\hline $\begin{array}{l}\text { Fast Track } \\
\begin{array}{l}\text { (Renda de Ativos+Rienda Port);Despesas Totais } \\
\text { Maior que } 1 \text { = Independência Financeira }\end{array}\end{array}$ & 0,00 \\
\hline
\end{tabular}

Fonte: Adaptado de Kiyosaki (2000)

No segundo cenário João com 46 anos, com salário de $\mathrm{R} \$ 8.500,00$, depois de algumas promoções, casado, sua esposa com 40 anos e renda mensal de $\mathrm{R} \$ 5.450,00$. Ele tem 1 filho, que estuda em escola particular. Neste estágio da vida, João observou um aumento expressivo das suas despesas e quer fazer uma nova análise. Na primeira parte João coloca em receitas os valores correspondentes ao seu salário (\#salário1) e o salário de sua esposa (\#salário2), na parte das despesas, além das despesas com INSS (outras despesas) e IR, alimentação e vestuário, ele tem a parcela do financiamento da casa em que mora, a despesas referente ao carro da família que é um carro por assinatura e a mensalidade da escola do seu filho, o plano de saúde é benefício disponibilizado pela empresa para João, sua esposa e filho.

Ao avaliar o seu fluxo ele nota que ainda está com fluxo de caixa positivo, mas fica preocupado que o valor destinado a investimentos diminuiu.

\section{Quadro 4: Segundo cenário do João}




\begin{tabular}{|c|c|c|c|c|}
\hline \multicolumn{2}{|l|}{ RECEITAS } & \multicolumn{3}{|l|}{ DESPESAS } \\
\hline SALARIOS [Brutos] & & DESPESAS & & \\
\hline Salário \#1 & $8.500,00$ & Imposto de Renda & $\mathrm{R} \$$ & $1.618,32$ \\
\hline Salário \#2 & $5.450,00$ & IPTU [imóvel próprio] & $\mathrm{R} \$$ & 120,00 \\
\hline Total Salários & $13.950,00$ & Financiamento imovel próprio & $\mathrm{R} \$$ & $2.500,00$ \\
\hline RENDA DE ATIVOS TANGIVEIS & & Contas imóvel próprio & $\mathrm{R} \$$ & 850,00 \\
\hline Imóvel (líquido + IR) & & Manutenção imóvel próprio & $\mathrm{R} \$$ & 400,00 \\
\hline Negócio (líquido + IR) & & Seguros imóvel próprio & $\mathrm{R} \$$ & 120,00 \\
\hline Total Renda de Ativos & $\mathrm{F}$ R\$ & Alimentação e vestuário & $\mathrm{R} \$$ & $2.500,00$ \\
\hline RENDA DE ATIVOS DE PORTFOLIO & & Dutras despesas & $\mathrm{R} \$$ & $1.366,28$ \\
\hline Juros & & Caridade l Doações & $\mathrm{R} \$$ & - \\
\hline Dividendos & & Cartão de crédito 1 & $\mathrm{R} \$$ & $1.280,00$ \\
\hline Royalties & & Cartão de crédito 2 & $\mathrm{R} \$$ & - \\
\hline Total Renda de Portfolio & $\overline{\mathrm{F}} \$$ & Financiamento carro 1 & $\mathrm{R} \$$ & - \\
\hline & & Financiamento carro 2 & $\mathrm{R} \$$ & - \\
\hline RECEITAS TOTAL & R5 13.950 .00 & mensalidade escolar 1 & $\mathrm{R} \$$ & 650,00 \\
\hline & & mensalidade escolar 2 & $R \$$ & 1.0 \\
\hline & & DESPESAS TUTAIS & Rs & $11.404,60$ \\
\hline & & Fluxo de Caíxa (receitas-despesa & RS & $2.545,40$ \\
\hline
\end{tabular}

Fonte: Adaptado de Kiyosaki (2000)

Ao avaliar a segunda parte da planilha o Balanço Patrimonial da família, no que tange a remuneração proveniente dos ativos, os investimentos, como juros e dividendos, estes são totalmente reinvestidos. A casa financiado, gera um passivo oneroso, assim como o restante das parcelas referentes ao financiamento imobiliário. Por adquirir tal ativo financiado ele passa a ter passivos que segundo Kiyosaki (2000) não devem compor o patrimônio líquido da família, sendo este o total de ativos (sem ativos acessórios) menos o passivo.

Importante ressaltar que no caso do veículo, o valor da assinatura é debitado no cartão de crédito e por isso classificado como passivo no balanço patrimonial (R\$ 1.280,00), desta forma João evita a depreciação do bem, e gastos como IPVA, licenciamento e seguro.

\section{Quadro 5: Segundo cenário do João}

\begin{tabular}{|c|c|c|c|c|}
\hline \multicolumn{2}{|l|}{ ATIVOS } & \multicolumn{3}{|l|}{ PASSIVOS } \\
\hline \multicolumn{2}{|l|}{ ATIVOS } & \multirow{6}{*}{$\begin{array}{l}\text { PASSIVOS } \\
\text { Cartões de crédito } \\
\text { Financiamentos de carros } \\
\text { Financiamentos escolares } \\
\text { Hipotecas imobiliárias } \\
\text { Empréstimos pessoais } \\
\text { Qutros passivos }\end{array}$} & & \\
\hline Investimentos bancários & $222.166,00$ & & $\mathrm{R} \$$ & $1.280,00$ \\
\hline Ações & $76.367,00$ & & & \\
\hline Títulos & & & & \\
\hline $\begin{array}{l}\text { Recebiveis } \\
\text { Imóveis (investimento) }\end{array}$ & & & $\mathrm{R} \$$ & $150.000,00$ \\
\hline 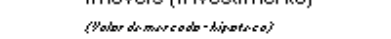 & & & & \\
\hline Valor líquido dos negócios & & TOTAL DE PASSIVOS & Rs & $151.280,00$ \\
\hline \multicolumn{2}{|l|}{ TOTAL DE ATIVOS } & \multirow{7}{*}{ 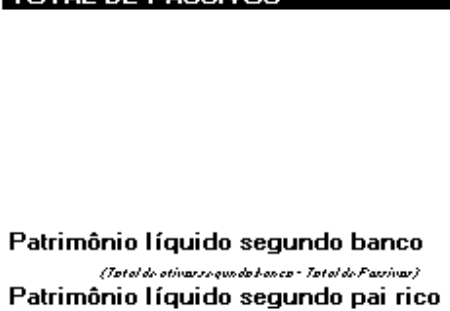 } & & \\
\hline & & & \\
\hline & $250.000,00$ & & & \\
\hline & & & & \\
\hline TOTAL DE ATIVOS ACESSÓRIC & R\$ 250.000 .00 & & & \\
\hline \multirow{3}{*}{ 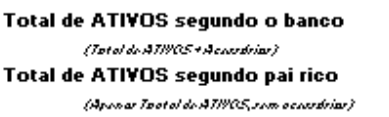 } & R\$ $548.533,00$ & & RS & 397.253 .00 \\
\hline & R\$ $298.533,00$ & & RS & $147.253,00$ \\
\hline & & 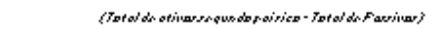 & & \\
\hline
\end{tabular}

Fonte: Adaptado de Kiyosaki (2000) 
Importante destacar, que o imóvel utilizado para moradia e o automóvel para uso próprio, não são investimentos, segundo Cerbasi (2013). Eles são um consumo, uma vez que o dinheiro consumido não pretende multiplicar-se, o valor destinado a adquirir este bem não se propõe que este seja multiplicado, e caso o imóvel venha a ser valorizado a tendência é que a família venda para comprar um de igual valor ou superior.

Conforme demonstra a terceira parte da planilha, neste determinado momento João e sua família estão poupando menos que aos 25 anos. Anteriormente seu indicador de fluxo de caixa/ Receitas totais era de $42 \%$, e neste momento é de $18,25 \%$, isso se deve ao valor que desprende para moradia (Despesas de moradia/ receitas totais) de 28,6\%. Porém este valor ainda dentro da proposta de utilizar no máximo 33\%. Quando apresentado o indicador ativos acessórios (Moradia) com 45,58\%, João nota que o alto valor do imóvel adquirido está impactando diretamente na sua capacidade de investir. Ressalta-se o problema das grandes metrópoles brasileiras que apesar de disponibilizar as remunerações mais atrativas, tem alto custo de vida. No caso de João, por ainda estar dentro da sua proposta de poupar o mínimo de $14 \%$ ao mês para investimentos ele pondera as possibilidades e entende que a mudança poderia gerar despesas maiores com deslocamento.

\section{Quadro 6: Segundo cenário do João}

\begin{tabular}{|c|c|}
\hline ANALISE & \\
\hline $\begin{array}{l}\text { Quanto você guarda? } \\
\text { Fluxo de CaixalReceitas Total } \\
\text {..'Deve esta aumentando }\end{array}$ & $18,25 \%$ \\
\hline $\begin{array}{l}\text { Seu dinheiro trabalha para você? } \\
\text { (Renda Ativos+Rienda Portf.)PReceitas Tota } \\
\text {..Deve estar aumentando }\end{array}$ & $0,00 \%$ \\
\hline $\begin{array}{l}\text { Quanto você paga de imposto? } \\
\text { Imposto de rendaPieceitas Total }\end{array}$ & $11,60 \%$ \\
\hline $\begin{array}{l}\text { Quanto você gasta para morar? } \\
\text { Despesas de moradiaReceitas Tota } \\
\text {..mantenha abiaxo de } 33 \%\end{array}$ & $28,60 \%$ \\
\hline $\begin{array}{l}\text { Quanto você gasta em acessórios? } \\
\text { Ativos AcessóriosłAtivos segundot } \\
\text {.'-mantenha abaino de } 33 \%\end{array}$ & $45,58 \%$ \\
\hline Qual o seu retorno annual sobra ativos? & \\
\hline $\begin{array}{l}\text { Renda Ativos+Renda Port.tAtivos segundo } \\
\text {-.'deve estar aumentando }\end{array}$ & $0,00 \%$ \\
\hline $\begin{array}{l}\text { Quanto rico você é? } \\
\text { Ativos segundo pai ricolDespesas Totais } \\
\text {..'medido em Meses }\end{array}$ & 26,2 \\
\hline $\begin{array}{l}\text { Fast Track } \\
\qquad \begin{array}{l}\text { (Renda de Ativos+Renda Port)]Despesas Totais } \\
\text { Maior que } 1=\text { Independência Financeira }\end{array}\end{array}$ & 0,00 \\
\hline
\end{tabular}

Fonte: Adaptado de Kiyosaki (2000) 
Por fim, ao chegar aos seus 65 anos, João passará a receber sua aposentadoria através do INSS, bem como sua esposa (\#salário1 e \#salário2 respectivamente).

A simulação do cenário foi realizada com o valor atual da aposentadoria recebida pelo casal, com correção anual de $2 \%$ (dois por cento) e ajustes nas despesas cosiderando a idade do casal.

Nessa etapa, João começa a realizar os resgates de juros e dividendos dos seus investimentos para complentar a renda do casal e manutenção do padrão de vida adquirido ao longo da vida, tendo em vista que a queda dos salários da ativa é evidente. O planejamento ao longo de toda sua vida, nesse momento, torna-se de suma importância para sua subexistência, uma vez que o seu fluxo de caixa passa a ser negativo, ou seja, os seus gastos excedem suas receitas, além disso, caso João não tivesse a renda proveniente dos juros e dividendos o seu padrão de vida teria que ser reduzido drasticamente.

\section{Quadro 7: Terceiro cenário do João}

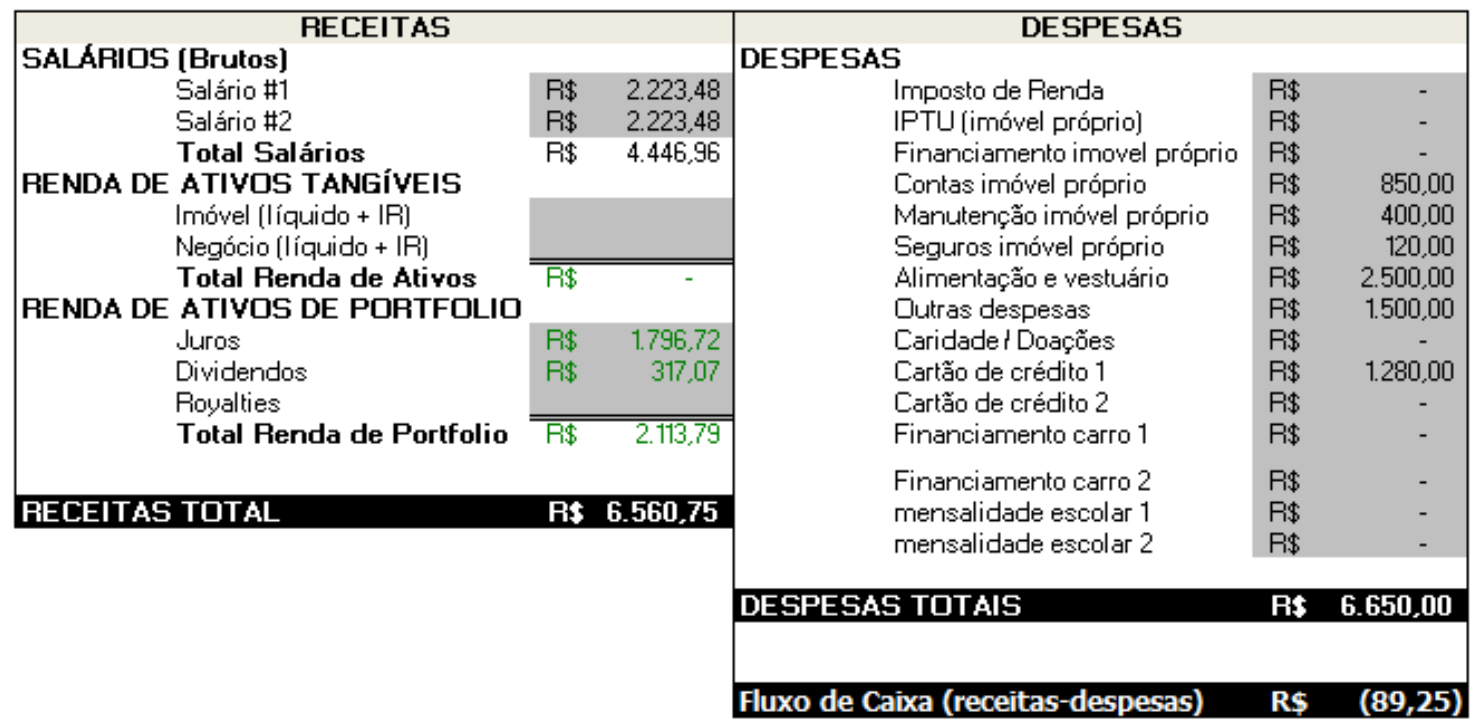

Fonte: Adaptado de Kiyosaki (2000)

Segundo Kiyosaki (2000) o total de seus investimentos, que por sua vez será utilizado conforme sua estimativa de vida (80 anos), equivale ao valor do patrimônio líquido, uma vez que sua casa e carro foram quitados $(\mathrm{R} \$ 650.217,00)$ desconsiderando sua moradia (ativo acessório), mesmo quitada, por não ser um multiplicador de valor. Assim João e sua esposa dispõem do total de $\mathrm{R} \$$ 650.217,00 (patrimônio líquido segundo pai rico) para usufruir. 
Quadro 8: Segundo cenário do João

\begin{tabular}{|c|c|c|c|}
\hline \multicolumn{2}{|l|}{ ATIVOS } & \multicolumn{2}{|l|}{ PASSIVOS } \\
\hline 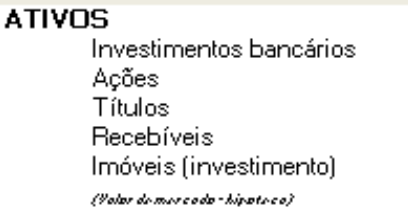 & $\begin{array}{ll}\mathrm{R} \$ & 521.198,00 \\
\mathrm{R} \$ & 130.299,00\end{array}$ & $\begin{array}{l}\text { PASSIVOS } \\
\text { Cartões de crédito } \\
\text { Financiamentos de carros } \\
\text { Financiamentos escolares } \\
\text { Hipotecas imobiliárias } \\
\text { Empréstimos pessoais } \\
\text { Dutros passivos }\end{array}$ & $1.280,00$ \\
\hline Valor líquido dos negócios & & TOTAL DE PASSIVOS & 1.280 .00 \\
\hline TOTAL DE ATIVOS & Rs 651.497 .00 & & \\
\hline $\begin{array}{l}\text { ATIVOS ACESSÓRIOS } \\
\text { Casa própria (moradia) } \\
\text { Automóveis para uso próprio } \\
\text { Outros }\end{array}$ & $350.000,00$ & & \\
\hline OTAL DE ATIVOS ACESSORI & Rs 350.000 .00 & & \\
\hline Total de ATIYOS segundo o banco & R\$ $1.001 .497,00$ & Patrimônio líquido segundo banco & R\$ 1.000 .217 .00 \\
\hline 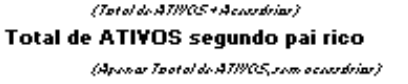 & Rs $651.497,00$ & 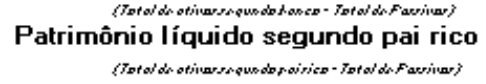 & R\$ $650.217,00$ \\
\hline
\end{tabular}

Fonte: Adaptado de Kiyosaki (2000)

Neste momento por passar a usufruir de seus investimento o quadro de análise pode ser desconsiderado uma vez que ele não esta evoluindo seus investimentos e não tem intenção de atingir a sua independência financeira (fast track).

Conclui-se que o modelo Pai Rico, Pai Pobre pode ser adaptado ao jovem brasileiro de modo prático, pois realizando a leitura dos cenários percebe-se o sucesso do modelo na vida do João. Isso encoraja o início de uma jornada de investimentos para os jovens, num país que pouco se fala em poupar para o futuro e com alto índice de endividamento. Esse é o principal ponto de análise, evidenciar como uma poupança pode influenciar suas decisões no futuro e a partir disso trilhar seu caminho. A vida é feita de obstáculos, sacrifícios e recompensas e é essa cultura que precisamos trabalhar em nosso país.

É importante também, considerar a inflação e contextos locais como crises econômicas, desempregos e imprevistos. Atualmente estamos vivendo uma pandemia do COVID 19 em que milhares de pessoas se viram sem renda e sem nenhum suporte. E aí, como seria a vida do João nesse contexto?

O planejamento financeiro é algo importante em todas as etapas da vida e o momento da aposentadoria deve ser de felicidade e sensação de dever cumprido de todo trabalhador. Planejar pode trazer recursos financeiros, mas também traz dignidade para a vida de todos. 


\section{REFERÊNCIAS}

BANCO CENTRAL DO BRASIL. Caderno de Educação Financeira: Gestão de

Finanças Pessoais. Brasília: Banco Central do Brasil, 2013. Disponível em:

<https://www.bcb.gov.br/content/cidadaniafinanceira/documentos_cidadania/Cuidando _do_seu_dinheiro_Gestao_de_Financas_Pessoais/caderno_cidadania_financeira.pdf>. Acesso em: 04 abr.2021

CERBASI, Gustavo. Investimentos Inteligentes. Rio de Janeiro: Sextante, 2013.

CERBASI, Gustavo. Como organizar sua vida financeira. Rio de Janeiro: Sextante, 2012.

FARIA, Luiz Henrique Chaves de. Planejamento Financeiro Pessoal. Disponível em: <https://repositorio.uniceub.br/jspui/bitstream/235/8984/1/20551138.pdf>. Acesso em: 02. abr. 2021.

FERREIRA, Juliana Cezario. A importância da educação financeira pessoal para a qualidade de vida. v.1. Ano 2017.

GAMA, Bruna Soares da. Planejamento financeiro pessoal e a importância da gestão dos próprios recursos - Um estudo de caso com os estudantes de Administração da Faculdade Paraíso do Ceará - FAP CE. Disponível em: $<$ https://semanaacademica.org.br/system/files/artigos/bruna.pdf>. Acesso em: 02. abr. 2021.

KHATIB, Ahmed. Afinal, o que é Alfabetização Financeira? Um estudo sobre os conceitos presentes na literatura. Disponível em:

$<$ https://administradores.com.br/artigos/afinal-o-que-\%C3\%A9alfabetiza\%C3\%A7\%C3\%A3o-financeira>. Acesso em: 02. abr. 2021.

KIYOSAKI, Robert. Pai rico, pai pobre. São Paulo: Ed. Campus, 2000.

MALASSISE, Regina Lúcia Sanches; KFOURI, Ana Vitória; SAMPAIO, Helenara Regina. Apostila - Básico em finanças pessoais. Disponível em: 
Educação financeira: aplicação das lições do Pai Rico, Pai Pobre à realidade de um

jovem brasileiro

<https://educapes.capes.gov.br/bitstream/capes/430564/2/Apostila\%20B\%C3\%A1sico \%20em\%20Finan\%C3\%A7as\%20Pessoais.pdf>. Acesso em: 02. abr. 2021.

Resumo Cast. Pai Rico, Pai Pobre - Planilha Financeira - Parte 1. Disponível em: < https://www.youtube.com/watch?v=HX2kh9Vt1qw>. Acesso em 27. abr. 2021.

Resumo Cast. Pai Rico, Pai Pobre - Planilha Financeira - Parte 2. Disponível em: < https://www.youtube.com/watch?v=ts1189I3gAs>. Acesso em 27. abr. 2021.

CONQUER. Curso Inteligência Financeira. Escola Conquer. 2020. Disponível em: < https://escolaconquer.com.br/?gclid=CjwKCAjwqeFBhAsEiwA2G7N14BCrGOsXcmCwcF7K_ZQyhnszc43HBy7izHSIUJz2MCUavM YCEWTKRoCGxQQAvD_BwE>. Acesso em: 23. Maio. 2021.

WATAYA, Roberto Sussumu. FRAUCHES, Patricia. BERGAMO, Andressa Ferreira. Finanças pessoais na palma da mão: um relato de experiência. Revista Científica Multidisciplinar Núcleo do Conhecimento. Ano 05, Ed. 07, Vol. 05, pp. 109124. Julho de 2020. ISSN: 2448-0959, Link de acesso: https://www.nucleodoconhecimento.com.br/tecnologia/financas-pessoais, DOI: 10.32749/nucleodoconhecimento.com.br/tecnologia/financas-pessoais NBC TG ESTRUTURA CONCEITUAL - ESTRUTURA CONCEITUAL PARA RELATÓRIO FINANCEIRO. Disponível em: < https://www1.cfc.org.br/sisweb/SRE/docs/NBCTGEC.pdf>. Acesso em: 23. maio. 2021. 